\title{
An Integrated Process of Methanol Coagulation and Side Stream Membrane Bioreactor for Treatment of Rice Gruel Wastewater
}

\author{
Shaik Nazia \\ "RMIT University" \\ Karishma Mishra \\ Indian Institute of Chemical Technology \\ Veeriah Jegatheesan \\ "RMIT University" \\ Suresh K Bhargava \\ "RMIT University"
}

Sridhar Sundergopal ( $\nabla$ sridhar11in@yahoo.com )

Council for Scientific and Industrial Research Natural Resources and the Environment

\section{Research}

Keywords: Rice gruel wastewater, Coagulants, Hydrophilized - ultrafiltration (HF - UF) 5 kDa membrane, Aerobic Membrane Bioreactor

Posted Date: July 21 st, 2020

DOl: https://doi.org/10.21203/rs.3.rs-39334/v1

License: (c) (1) This work is licensed under a Creative Commons Attribution 4.0 International License. Read Full License 


\section{Abstract}

The demand for water supply is expected to be raised significantly in forthcoming decades. Production of reusable water from industrial and domestic wastewater is a feasible, cost effective and significant positive benefit to the environment. In the present study, the domestic rice gruel wastewater (RGW) was treated with aqueous methanol coagulation integrated aerobic membrane bioreactor (AMBR). Initially, the RGW which is at room temperature was treated with spiral wound hydrophilized - ultrafiltration (HF - UF) $5 \mathrm{kDa}$ membrane module to determine the removal efficiency. Furthermore, the RGW was pre-treated with various coagulants such as methanol, ethanol and $\mathrm{HCl}$. The obtained pre-treated RGW was subjected to the HF - UF $5 \mathrm{kDa}$ side stream AMBR for production of reusable water. The experiments were conducted to determine the turbidity, conductivity, total dissolved solids (TDS) and chemical oxygen demand (COD) were found to be $96 \%, 91 \%, 91 \%$ and $94.6 \%$. The overall process was feasible, compact, environmental free, cost effective, eco-friendly.

\section{Introduction}

In recent decades, water demand is officially looking for few substitutionally resources to satisfy the enhancing affirmation due to the augmenting population, urbanization, population growth, expansion of integrated agricultural etc., $[1,2]$. Hence, it has become a special interest in arid and water-scarce countries such as Iran, India, Italy, Iraq, Portugal etc., [3]. Most of the water resources are contaminated by domestic and industrialization for urban development. The treatment of wastewater is an important factor for environmental application whereas, the domestic wastewater is considered as a strategic method for production of reusable water.

Moreover, two-thirds of the entire world population was consumed rice as a staple food, mostly $95 \%$ rice is being consumed by oriental countries like India, Bangladesh, China, Japan, Korea, Philippines, Malaysia, Indonesia, Thailand, Sri Lanka, etc. Cooking of rice produces a large amount of rice gruel and discharged to land as a wastewater [4,5]. The Rice gruel (RG) is one of the domestic wastewater, consists of a significant amount of starch, protein, lipids and suspended solids which need to be separated before discharge into water sources [6]. Amylose and amylopectin are two components of starch ranging in average molecular weight from 5,200 (5 kDa) to 872,300 (870 kDa). While Amylose is a long, straight starch molecule that does not gelatinize during cooking whereas amylopectin is a highly branched starch molecule that is responsible for making rice gelatinous and sticky. It also evolves foul odour due to bacterial growth when exposed to environment.

Hence, the Rice gruel wastewater (RGW), is directly discharged into water bodies by restaurants, hotels, hostels, household, monasteries etc., [7, 8]. Most of the conventional wastewater treatment processes such as ion exchange, adsorption, electrochemical treatment, chemical precipitation, adsorption, solvent extraction, flotation were used to extract the major component starch which was present in the RGW [9, 10]. However, the conventional processes have some limitations due to the high-power consumption, large space requirements, additional of chemicals or solvents for separation, phase change [11]. 
Therefore, there is need to develop an alternative technology for treatment of domestic wastewater reclamation.

Advanced membrane separation processes include reverse osmosis (RO), nanofiltration (NF), ultrafiltration (UF), microfiltration (MF), membrane bioreactor (MBR) were extensively used for treatment of domestic wastewater [12]. Among those MBR is widely enhancing technology for domestic wastewater treatment in aerobic and anaerobic condition. Anaerobic treatment system can remove chemical and biological oxygen demand along with carbohydrates, proteins and other constituents. The generation of biomethane from the anaerobic treatment can be another significant product as an energy supplement. However, anaerobic processes have their limitations including the production of foul, odour, low reduction in turbidity and total dissolved solids (TDS) etc., [13]. Hence, most of the researchers have been used aerobic treatment process to supply enough oxygen to support the bacteria which can reduce the organic and inorganic compounds.

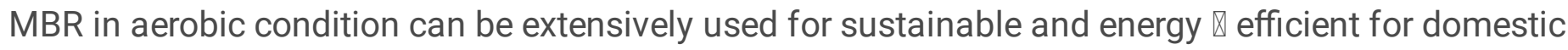
wastewater such as laundry [14], kitchen [15], Bathroom [16], washing machine water [17] for reproducibility of water. The AMBR can be further integrated with the conventional process to achieve high energy consumption, huge operation and less maintenance cost. A very few studies were reported on domestic RGW by AMBR. Boykin et al 2005 studied concentrating of starch from rice cooker wastewater using MF membrane [18]. Sayanthan and Thusyanthy 2018 reviewed rice parboiling and effluent treatment model [19]. Bovas and james developed membrane bioreactor in anaerobic conditions for rice mill effluent treatment with less energy conservation [20]. Mananta and Bhattacharya 1989 extracted the rice starch from parboiled rice starke in thermal degradation process [21]. Choudhary et al., 2015 used electrocoagulation process for the treatment of rice mill effluent [22].

From the literature survey, this is the first kind of study for the treatment of RGW using coagulation processes integrated with AMBR. Pretreatment of RG with different coagulants such as methanol, ethanol and $\mathrm{HCl}$ for sedimentation of heavy suspended solids. Further, the RG was treated with HF - UF AMBR for reproducibility of potable water. Experiments were conducted to estimate the turbidity, COD, TDS, $\mathrm{pH}$ and conductivity on membrane performances. From the experimental results, the process was scaled up and calculated the cost of the process.

\section{Material And Methods}

\section{Material}

Polyethersulfone (PES) polymer was purchased from Solvay, Vadodara, India. Polyvinyl alcohol (PVA), Polyethylene glycol (PEG) of different molecular weights, ethanol, methanol, hydrochloric acid ( $\mathrm{HCl})$, glutaraldehyde (GA) and Dimethylformamide solvent (DMF) were purchased from S.D. Fine Chemicals Ltd., Mumbai, India. The non-woven polyester fabric was procured from Miki Tokushu Paper Mfg. Co. Ltd., Japan to be used as the support for casting the hydrophilized (HF) - UF (ultrafiltration) membranes. The nutrient broth and agar were supplied by Hi-Media Lab. Pvt. Ltd. Mumbai, India. The indigenous 
synthesized HF - UF membrane was spirally wound with assistances of Permionics Pvt. Ltd., Vadodara, India. Glass wear such as a conical flask, beakers, Petri dishes, measuring cylinders, were used to prepare the agar broth and analysis of the collected samples obtained from vasco scientific from Hyderabad, India. Equipment's such as autoclave (Equitron Medica Instrument, Mumbai, India), laminar flow chamber (Lab Tech, Mumbai, India), weighing machine (Sartorius, Hyderabad, India), Refractive Index (AntonPaar, Type: Abbemat 200, Mumbai, India) and incubator were supplied by Secunderabad India. The hardware items such as aerator, pressure gauge, valves, pump, $T$ - joint, telfon, cotton, tubing, parafilm, strips, for installation of MBR system which was supplied by SVS water solution for experimental setup, Hyderabad, India. Deionized water for water bath was prepared using the laboratory ultrapure cascaded reverse osmosis (RO) system.

\section{Methods}

\section{Synthesis of hydrophilized (HF) - ultrafiltration (UF) 5 kDa membrane}

HF - UF membrane was synthesized using immersion precipitation method by phase inversion technique. The blend polymer solution for casting was prepared by adding the $2 \mathrm{wt} \%$ of PVA and $23 \mathrm{wt} \%$ of PES and $0.5 \mathrm{ml}$ of GA to the $74.5 \mathrm{ml}$ of DMF solvent (wt/vol as per polymer weight) under continues stirring for $12-18 \mathrm{~h}$ at $50^{\circ} \mathrm{C}$. The mixture was kept stagnant at room temperature $\left(30 \pm 2{ }^{\circ} \mathrm{C}\right)$ to remove the presence of excess bubbles in the polymer solution. The bubble-free solution was poured on the polyester non-woven fabric support fixed on a glass plate using the doctor's blade for the desired thickness and immediately immersed in the non-solvent bath (pure water) at room temperature (30 \pm 2 $\left.{ }^{\circ} \mathrm{C}\right)$ to obtain HF - UF membrane.

\section{Effect of molecular weight of Polyethylene glycol (PEG)}

PEG with molecular weights of 6,000 and 4,000 Da were dissolved in deionized water to prepare $1 \mathrm{~L}$ aqueous solutions to assess MWCO and rejection of solvents through synthesize HF - UF membrane. Rejection measurements were performed at a pressure of 3 bar using the PEG solution as the basis for feed. The concentration of feed, permeate and retentate solution was then determined via Refractive Index.

\section{Sample collection}

Rice gruel wastewater (RGW) used in the present work was obtained from the Akshaya Patra Foundation, Hyderabad, India. Initially, the sample was pretreatment with alcohol and $\mathrm{HCl}$ before subjected membrane filtration. The overall experimental manifold was provided in Fig. 1a.

\section{Treatment of cold and hot RGW by spiral wound HF - UF 5 kDa membrane}

The RGW which was at room temperature and hot $\left(80^{\circ} \mathrm{C}\right)$ were passed though the spiral wound UF module with membrane area $1.2 \mathrm{~m}^{2}$ for $3 \mathrm{~h}$ and the feed permeate and retentate samples were used for physicochemical analysis, respectively. 


\section{Pretreatment of RGW with coagulants}

Wastewater treatment (WWT) processes involves a series of physical, chemical and biological treatment techniques were further classified into pretreatment, primary and secondary treatment [23]. In the present study, the coagulation pretreatment for RGW domestic wastewater was pretreated for soluble removal of organic matter. The coagulation step was carried out by alcohols and acids to stabilize the starchy colloidal content, which eliminates moderate levels of total dissolved solids (TDS), chemical oxygen demand (COD), $\mathrm{pH}$, conductivity and turbidity. During the pretreatment step, the hot raw RGW was allowed to cool at room temperature and $6.5 \mathrm{~L}$ feed was collected in a container and treated with $1 \% \mathrm{HCl}$ solution. The reaction mixture was stirred at $250 \mathrm{rpm}$ for about $30 \mathrm{~min}$ and allowed for $2 \mathrm{~h}$ to sedimentation as shown in Fig. $1 \mathrm{~b}$. The same experiments were repeated with methanol and ethanol as pre-treatment coagulants. Among that methanol, coagulant shows higher removal efficiency in suspended from RGW.

\section{Experimental setup for spiral wound UF membrane}

After the preliminary pretreatment with the methanol the supernatant liquid was passed through the spiral wound HF - UF membrane module membrane area $1.2 \mathrm{~m}^{2}$ at 3 bar pressure using $300 \mathrm{gpd}$ (gallon per day) pump. The experiments were performed in a continuous mode, by measuring the permeate flux with respect to time, whereas the concentrate was recycled back to the feed tank. The UF process flow diagram was provided in Fig.1c the pretreatment method and UF experimental system.

\section{Preparation of culture and nutrient agar}

For the development of microbial consortia, it is necessary to prepare a culture media using a nutrient agar and broth. The agar medium was prepared by dissolving of $28.0 \mathrm{~g}$ of agar in $1 \mathrm{~L}$ distilled water and sterilized using autoclaved at a pressure of $15 \mathrm{lbs}$ for $45 \mathrm{~min}$ by maintaining the temperature $121^{\circ} \mathrm{C}$ for sterilization. The agar medium was allowed to cool for $1 \mathrm{~h}$ at room temperature and poured into a Petri dish under laminar airflow until it solidifies. The medium was subsequently streaked on the Petri dish and kept in an incubator at $37^{\circ} \mathrm{C}$ for one day.

\section{Preparation of nutrient broth}

$13.0 \mathrm{~g}$ of nutrient broth was uniformly mixed with $1 \mathrm{~L}$ of distilled water and subjected to the autoclave for sterilization at $121^{\circ} \mathrm{C}$ using $15 \mathrm{lbs}$ pressure for $30 \mathrm{~min}$. The grown culture $(50 \mathrm{ml})$ from nutrient agar was added to the nutrient broth and kept in the incubator for one day at $37^{\circ} \mathrm{C}$. The culture was added to the feed tank and stayed overnight for further microbial growth followed by adaptation within the RGW environment.

Experimental setup and procedure for pretreatment coagulation and integrated aerobic membrane bioreactor (AMBR) 
In this experimental study, after the preliminary pretreatment of RGW step with the chemicals $(\mathrm{HCl}$, ethanol, and methanol) the supernatant was passed through the side-stream AMBR for to remove suspended solids, turbidity, color. Fig. 1d represents the process flow diagram AMBR where the feed tank capacity of $2.5 \mathrm{~L}$ was connected to the spiral UF membrane module with membrane area $1.2 \mathrm{~m}^{2}$ connected to $300 \mathrm{gpd}$ pressure pumps. The module was arranged in a cross-flow manner and the permeate was collected into permeate tank, the retentate was fed back to the feed tank with the pressure gauge and control were fixed at the retentate line.

Initially, a mixed culture aerobic medium was added to the pre-treated RGW wastewater present in the feed tank (2L). A micro-bubble diffuser was assembled in the feed tank for providing oxygen and controlling the aerobic conditions for the growth of biomass. The feed was fed to the membrane by maintaining the feed pressure of 3 bar throughout the experiments. The initially feed, permeate and retentate samples were collected for the analysis. The experiments were continued for 18 days in aerobic condition to remove the TDS, colour, conductivity and COD.

\section{Membrane characterization}

Indigenous membranes were characterized by Fourier transform infrared spectroscopy (FTIR), X - ray diffraction (XRD) analysis and Scanning electron microscope (SEM). For SEM studies, the membrane was cut into the liquid nitrogen and subjected to the SEM (JEOL JSM 5410, Japan) with a model number for 20 and $200 \mu \mathrm{m}$.

The X - ray pattern of the membrane was determined by XRD D 5000 (NJ, USA) to understand the crystalline nature of the polymer membrane. The $X$ - ray diffract gram was obtained by the Bragg's equation to determine $2 \theta$ valves of the polymer.

FTIR spectroscopy was carried out using a Shimadzu, Japan instrument for analysing the formation of new functional groups and intermolecular interactions after membrane formation.

\section{Membrane fouling}

The membrane fouling caused by suspended particles, microbes, inorganic and organic components present in the feed that can accumulate, salts, and organic compounds present in the feed water that accumulate on surface of membrane and pores. Therefore, the membrane fouling was reduced by removing module from the system and clean at regular time intervals, after every batch experiment using chemical washing followed by water washing at low pressure. The chemical washing was conducted using $1 \%$ citric acid, $1 \%$ sodium hydroxide $(\mathrm{NaOH})+0.5 \%$ ethylene diamine tetraacetic acid (EDTA) + $0.1 \%$ of sodium lauryl sulfate (SLS) for $30 \mathrm{~min}$ followed by water wash (30 min) after acid and alkaline wash. After chemical cleaning, the scalant have been completely removed from the surface of the membrane $[24,25,26,27]$. After chemical cleaning the membranes was stored in sodium metabisulphite (SMBS) $(0.5 \% \mathrm{w} / \mathrm{v})$ aqueous solution to avoid further biological fouling and extend the life span of the membrane. 


\section{Analytical methods}

Raw industrial wastewater, pretreated supernatant (after coagulation), permeate samples were analysed in relation to $\mathrm{pH}$, colour, Conductivity $(\mathrm{mS} / \mathrm{cm})$, turbidity (FAU), TDS $(\mathrm{mg} / \mathrm{L})$ according to the standard procedure for wastewater analysis [28]. Sample $\mathrm{pH}$ was determined through a digital $\mathrm{pH}-$ meter (model DPH-504), at room temperature. Colour (Co- Pt), Turbidity (FAU) analysis was performed at (DR 800, HACH), TDS was determined using TDS meter with model HM TDS0-999, Hyderabad, India and Conductivity was measured using model DCM900 conductivity meter obtained from Global Electronics, Hyderabad, India.

\section{Mathematical tools}

\section{Permeate flux}

During the separation process, the permeate volume was determined by considering the effective membrane area and time, as shown in Eq. (1).

$$
\mathrm{J}=\frac{V}{A \times T}
$$

Where $J$ is the permeate flux $\left(\mathrm{L} / \mathrm{m}^{2} . \mathrm{h}\right), V$ is the collected volume of permeate $(\mathrm{L})$ in time $T(\mathrm{~h})$ and $A$ is the membrane area $\left(\mathrm{m}^{2}\right)$.

\section{Porosity}

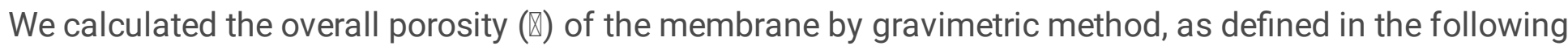
equation:

$$
\varepsilon=\frac{(m 1-m 2)}{s 1 \times \delta \times \rho}
$$

Where $m 1, m 2$ is the weight of the wet and dry membrane respectively, whereas $s 1$ is the surface area, $\delta$ is the cross-section thickness and $\rho$ is the density of the demineralized water.

\section{Rejection efficiency}

Rejection is another factor in which the membrane separation performance was evaluated by considering the turbidity, COD and PEG rejection in the permeate by Eq. (3).

$$
\mathrm{R}=\left[1-\frac{C p}{C f}\right] \times 100
$$


Where \% rejection denotes as $\mathrm{R}, C p$ and $C_{f}$ are the concentration of the solute in permeate and feed (mg/L).

\section{Chemical oxygen demand (COD)}

The quantity of the pollutes present in the permeate was determined after wastewater treatment is known as COD. The presence of higher organic pollutes present in the water the higher value of COD. Hence, the COD can be calculated from Eq. (4).

$$
\operatorname{COD}(\mathrm{mg} / \mathrm{L})=\frac{(B-S) * N * 8000 * D . F}{V}
$$

Where $B$ is the blank volume consumed in titration, $S$ is the volume consumed in titration with sample preparation 8000 is the equivalent weight of oxygen per $L, N$ is the Normality of standardized ferrous ammonium sulfate solution, D.F and $\mathrm{V}$ is known as dilution factor and the volume of the sample (ml).

\section{Results And Discussions}

\section{Membrane characterization}

\section{Structural analyses by fourier transform infrared spectroscopy (FTIR)}

Fig.2a represents the FTIR spectra of PES blended PVA cross - linked with GA membrane. The peak at $1117.78 \mathrm{~cm}^{-1}$ and $1435 \mathrm{~cm}^{-1}$ have attributed the ether $(\mathrm{C}=0)$ and sulfonated $\left(\mathrm{SO}_{2}\right)$ group of PES. This might be due to the stretching vibration of the aromatic ether. The peaks at $1582.63 \mathrm{~cm}^{-1}$ was denoted the aromatic benzene ring. In addition to this the board peak at around $3227 \mathrm{~cm}^{-1}$ indicates the starching vibration of the hydroxyl group of PVA. The formation of new acetol linkage was attributed at $1070 \mathrm{~cm}^{-1}$ which represent the cross - linking between GA and hydroxyl group of PVA. The possible reaction mechanism was provided in scheme 1 .

\section{Scanning electron microscopy studies (SEM)}

The morphology of surface and cross - section morphology of the HF - UF membrane was provided in Fig. 2b. The surface morphology of the membrane was observed to be porous with uniform distribution of pores throughout the membrane. From Fig.2b the blended PVA and PES substrate was interpenetrated into the polyester non-woven fabric support layer by the formation of finger - like structure, which can be evidently seen in Fig.2b. From surface and cross-sectional morphologies, the membrane was successfully formed a porous layer on the support.

\section{X-ray diffraction analysis (XRD)}


The nature of the polymer membrane was studied by X-ray diffraction pattern as depicted in Fig.2c. The membrane was appeared to be semi crystalline in nature, where the amorphous nature 0 to 37 on $2 \square$ without intensity. On the other hand, the sharp peaks were found to be 38 and 48 on $2 \varangle$ represent the crystalline nature of the polymer due to the cross linker. Therefore, the HF - UF membrane shows semi crystalline in nature and aptly suitable for the purpose of the study.

\section{Effect of Polyethylene glycol (PEG) concentrations on membrane compositions}

The membrane was passed through a $2 \mathrm{wt} \%$ of aqueous PEG solution to analyse the molecular weight cut off (MWCO) for the UF membrane. From Fig.3a, $b$ it can be seen that a linear relationship with two different PEG solutions i.e., 4,000 Da \& 6,000 Da. However, a higher rejection efficiency of $90 \%$ was achieved with 4,000 Da of PEG solution, which was accomplished with $2 \mathrm{wt} \%$ of the solution compared with 6,000 Da. Feed, permeate and retentate refractive index were shown in Fig.3c, where the refractive index for PEG 4,000 concentration lead to a highest \% rejection, and when the MWCO of PEG was 6,000 Da the \% rejection was decreased slightly. There was no further difference in the \% rejection efficiency with changes in molecular weight thereafter. Hence, this experiment demonstrates a rough ideation on average MWCO of $5000 \mathrm{Da}$. The calculated value of the porosity of $5 \mathrm{kDa}$ membrane was found to be $34.68 \%$, which concludes that the membrane MWCO was $5 \mathrm{kDa}$.

\section{Experimental Results For Treatment Of Rgw Effect of direct filtration using spiral wound HF - UF membrane}

Experiments were carried out based on the feed temperature to know the membrane performances. Initially, $5 \mathrm{~L}$ of RGW without coagulation was fed directly to the spiral wound HF - UF membrane with an operating pressure of 5 bar at room temperature $\left(28 \pm 2{ }^{\circ} \mathrm{C}\right)$. From Table 1 , the parameters namely $\mathrm{pH}$, TDS, turbidity, conductivity and COD values in the permeate at room temperature were found to be 3.34 , $56,330 \mathrm{mg} / \mathrm{L}, 1,200 \mathrm{FAU}, 84.3 \mathrm{mS} / \mathrm{cm}$ and 20,000 mg/L, respectively. Further, the effect of operating time on permeate flux was provided in Fig. $4 \mathrm{a}$, where the average flux decreased from 8.33 to $4.81 \mathrm{~L} / \mathrm{m}^{2} . \mathrm{h}$ by proceeding the operating time from 0 to $30 \mathrm{~min}$, respectively. The reason might be the formation of scalant on the membrane surface by direct filtration. In the second set of experiments the RGW was passed through the HF - UF membrane in hot condition i,e., the feed temperature was maintained at $80^{\circ}$ C. Initially, the pH of the RGW was 4.60 and removal efficiency of TDS, turbidity, conductivity and COD were found to be $62,330 \mathrm{mg} / \mathrm{L}, 1,325 \mathrm{FAU}, 34.3 \mathrm{mS} / \mathrm{cm}$ and 24,000 mg/L after membrane treatment, respectively. Moreover, from Fig. 4 a the average flux was decreased from 7.14 to $4.63 \mathrm{~L} / \mathrm{m}^{2}$.h with time from 0 to 30 min of experimental run, respectively. The flux declination was due to the accelerate of membrane fouling by suspended solids present in the effluent in hot condition [29]. The feed and permeate characteristics of RGW at room and hot conditions were provided in Table 1. From the results 
the treatment of RGW using HF - UF membrane shows better performance at room temperature than hot condition. Therefore, further experiments were conducted using RGW effluent at room temperature.

Table 1

Feed water characteristics of RGW effluent after treatment with HF - UF membrane in cold and hot conditions

\begin{tabular}{|llll|}
\hline Parameter & Feed & Feed at room temperature & Feed at $\mathbf{8 0}^{\circ} \mathbf{C}$ \\
\hline pH & 4.85 & 3.34 & 4.60 \\
\hline TDS $(\mathrm{mg} / \mathrm{L})$ & 67,392 & 56,330 & 62,330 \\
\hline Turbidity (FAU) & 1,500 & 1,200 & 1,325 \\
\hline Conductivity $(\mathrm{mS} / \mathrm{cm})$ & 105.3 & 84.3 & 34.3 \\
\hline COD $(\mathrm{mg} / \mathrm{L})$ & 28,000 & 20,000 & 24,000 \\
\hline
\end{tabular}

\section{Coagulation Based Integrated Hf - Uf Membrane System}

The RGW was pretreated with various coagulants such as methanol, ethanol and $\mathrm{HCl}$ and after treatment with HF - UF processes were studied. Initially, the colour of the RGW was found to be milky white at room temperature and the feed and permeate characteristics of TDS, turbidity $\mathrm{pH}$, Conductivity, and COD in integration with $\mathrm{HCl}+\mathrm{HF}-\mathrm{UF}$, ethanol + HF - UF and methanol + HF - UF efficiencies were provided in Table 2. From the experimental results, the methanol integrated UF membrane permeate characteristics were found to be $4,200 \mathrm{mg} / \mathrm{L}$ TDS, $70 \mathrm{FAU}, 7.23,6.528 \mathrm{mS} / \mathrm{cm}$ and $6,000 \mathrm{mg} / \mathrm{L} \mathrm{COD}$. On the other hand, the effect of operating time on permeate flux and \% rejection efficiencies were provided in Fig. 4b.The overall permeate flux, \% removal efficiencies of TDS, turbidity, conductivity and COD for $\mathrm{HCl}$, ethanol and methanol integrated process were found to be $7.7,8.2$ and $13.62 \mathrm{~L} / \mathrm{m}^{2}$.h with operating time $30 \mathrm{~min}$, respectively which is due to the formation of scalant on the membrane surface. Further, from Fig. $4 \mathrm{~b}$ the $\%$ efficiencies of TDS, turbidity, conductivity and COD were noted as $87.4,99.787 .4$ and $28.6 \%$ for $\mathrm{HCl}$ integration, $36.3,93.77,99.93,36.3$ and $53.6 \%$ for ethanol integration and finally $93.77,95.4,93.9,78.6 \%$ for methanol integration processes, respectively. The reason could be, after pretreatment of $\mathrm{HCl}$, the effluent can damage the surface of the membrane whereas, ethanol has vanderwall force between the molecules and suspended solids may take longer time to settle down. Therefore, methanol has opted as a coagulant for further continuation of experimental studies in integration with HF - UF membrane through aerobic membrane bioreactor (MBR). 
Table 2

Water quality parameters in feed and after coagulation integrated UF membrane process

\begin{tabular}{|c|c|c|c|c|c|c|}
\hline Parameters & $\begin{array}{l}\text { TDS } \\
(\mathrm{mg} / \mathrm{L})\end{array}$ & $\begin{array}{l}\text { Turbidity } \\
\text { (FAU) }\end{array}$ & $\mathrm{pH}$ & $\begin{array}{l}\text { Conductivity } \\
(\mathrm{mS} / \mathrm{cm})\end{array}$ & $\begin{array}{l}\text { COD } \\
(\mathrm{mg} / \mathrm{L})\end{array}$ & $\begin{array}{l}\text { Colour } \\
\text { (Pt-Co) }\end{array}$ \\
\hline $\begin{array}{l}\text { RGW (feed) after } \\
\text { cooling } \\
\text { to room } \\
\text { temperature }\end{array}$ & 67,392 & 1,500 & 4.85 & 105.3 & 28,000 & $\begin{array}{l}\text { Milky } \\
\text { White }\end{array}$ \\
\hline $\mathrm{HCl}(1 \%)+\mathrm{HF}-\mathrm{UF}$ & 8,512 & 4 & 1.61 & 13.3 & 20,000 & - \\
\hline $\begin{array}{l}\text { Ethanol }(1 \%)+\mathrm{HF}- \\
\text { UF }\end{array}$ & 42,880 & 1 & 3.34 & 67.4 & 13,000 & - \\
\hline $\begin{array}{l}\text { Methanol (1\%) + HF } \\
\text { - UF }\end{array}$ & 4,200 & 70 & 7.23 & 6.528 & 6,000 & - \\
\hline
\end{tabular}

\section{Influence of coagulant on aerobic membrane bioreactor (AMBR)}

The RGW effluent was pretreatment with methanol followed by treatment with HF - UF membrane bioreactor under the aerobic condition in continues recirculation for 18 days. The effect of operating time on permeates flux was provided in Fig.5a. The permeate flux decreased from 4.87 to $3.4 \mathrm{~L} / \mathrm{m}^{2}$.h with operating time from 0 to $30 \mathrm{~min}$, which is due to the formation of scalant on the surface of membrane by continues experimental run, respectively.

Further, from Fig. $5 b$ - 5e it can be clearly seen that the removal efficiency of turbidity, conductivity, TDS and COD in permeate were reduced from 1500 to $60 \mathrm{FAU}, 105.3$ to $9.5 \mathrm{mS} / \mathrm{cm}, 392$ to $5,760 \mathrm{mg} / \mathrm{L}$ and 28,000 to $1500 \mathrm{mg} / \mathrm{L}$ with a number of days from 1 to 18 , respectively. The $\mathrm{pH}$ of the effluent after treatment with AMBR increased from 4.85 acidic to neutral medium (pH -7.04) (Fig. 5f) with 18 days of operation. The overall percentage removal efficiency of the membrane with respect for turbidity, TDS, conductivity and COD were 96.0, 91.0, 91.0, 91.0 and $94.6 \%$, respectively. In this sense, methanol pretreatment along with AMBR is the best-suited system as this system will remove residual methanol entering the AMBR biologically. From Fig. $5 b$ - $5 f$ can be seen the AMBR becomes stable after 18 days of operation.

\section{Effect of membrane washing on pure water flux}

The membrane efficiency depends on the chemical washing which effects on pure water flux. After effluent treatment using UF membrane was washed thoroughly with organic and inorganic chemicals to determine the pure water flux for understanding the washing efficiency. Fig.6a reveals the decreased in the pure water flux from 136 to $87 \mathrm{~L} / \mathrm{m}^{2}$.h whereas, after membrane cleaning the flux was increased from 27.27 to $80.35 \mathrm{~L} / \mathrm{m}^{2}$.h with time from 0 to $3 \mathrm{~min}$, respectively. After membrane washing the pore on the 
membrane was effectively remove the scalant and particulates from the pores on the surface of the membrane.

\section{Construction of the molecular dynamic (MD) simulation}

A PES polymer chain for the MD simulation was carried out with repeating monomer units that were constructed and simulated using the Accelrys commercial software using the condensed phase optimized molecular potential for atomistic simulation study (COMPASS) force field [30]. The $3 \mathrm{D}$ structure of the PES, PVA and DMF as shown in (Fig.6b, c, d). The amorphous builder module was used to construct the system and minimization. PES was constructed by monomer PVA with repeating units and minimized by steepest - descent method.

Several cycles of energy minimization (EM) and MD simulation were repeated to allow the polymer chain to fold until the polymer structure had a density of $1.0003 \mathrm{~g} / \mathrm{cm}^{3}$, very close to the experimental density of PES, which was $1.37 \mathrm{~g} / \mathrm{cm}^{3}$ under ambient conditions [31]. After the first EM and MD simulation was performed at a constant elevated temperature at $298 \mathrm{~K}$ in the NVT (where the amount of N, volume (V) and Temperature $(T)$ ) statistical ensemble in order to speed up the process of folding of the polymer chain. The minimized structures of PES/PVA blend membrane at different hydration levels and an annealing MD simulation followed at the ambient conditions and the final structure of the PES bulk polymer model was shown in Fig. 6e.

\section{Energy minimization}

From Fig.6f shown that the potential energy increases during the process of molecular minimization. This is due to the energy replacement of $(\mathrm{OH})$ hydroxyl group from PVA. The amorphous systems were constructed with a periodic boundary condition and density of $1.0003 \mathrm{~g} / \mathrm{cm}^{3}$ after the minimization of each molecule. The minimization energy of the amorphous system with potential energy is -227.549 $\mathrm{kcal} / \mathrm{mol}$. Fig. $6 \mathrm{f}$ provides the information about how the water molecules are help for the increasing the total energy of the system.

\section{Economic Estimation For Integrated Membrane Bioreactor}

Usually, the conventional processes required enormous space, high energy consumption, chemical usage and labour cost compared to membrane process [32]. However, by considering environmental engineering drawbacks in low - pressure membrane processes for the production of potable water in various applications. Table 3 represents where a detailed description of the materials used in the present study for the installation of an experimental setup. The possible economic estimation was carried out for $1000 \mathrm{~L} / \mathrm{h}$ pilot scale was provided in Table 4 include operating and maintenance cost. The capital investment of the process was 5501.84 USD (INR 4.20 Lacs) with a payback period of 2.72 years. 
Table 3

List of items and capital equipment cost

\begin{tabular}{|c|c|c|c|c|c|c|}
\hline $\begin{array}{l}\text { S. } \\
\text { No }\end{array}$ & Item & Specifications & Material & $\begin{array}{l}\text { Qty. } \\
\text { No }\end{array}$ & $\begin{array}{l}\text { Total Cost } \\
\text { INR }\end{array}$ & $\begin{array}{l}\text { Total Cost } \\
\text { USD }\end{array}$ \\
\hline 1 & Feed tank & 2000 & Plastic & 1 & 10500 & 138.16 \\
\hline 2 & Feed pump & $1 \mathrm{HP}$ & Nil & 1 & 3500 & 46.05 \\
\hline 3 & Skid & $\begin{array}{l}1000 \mathrm{LPH} \\
\text { plant }\end{array}$ & SS & 1 & 2500 & 32.89 \\
\hline 4 & Multiport valve & Nil & Nil & 1 & 950 & 12.50 \\
\hline 5 & Pressure vessel & $3 \mathrm{~m}$ long & FRP & 1 & 2800 & 36.84 \\
\hline 6 & Sand (Bag) & Nil & Granular & 1 & 250 & 3.29 \\
\hline 7 & Carbon (Bag) & Nil & Granulated & 1 & 450 & 5.92 \\
\hline 8 & Jumbo pre-filter & Nil & Thread & 2 & 600 & 7.89 \\
\hline 9 & $\begin{array}{l}\text { Jumbo pre-filter } \\
\text { housing }\end{array}$ & Nil & Nil & 2 & 800 & 10.53 \\
\hline 10 & Bioreactor unit & Nil & Polyacrylic & 1 & 300000 & 3947.37 \\
\hline 11 & High pressure pump & $1.5 \mathrm{HP}$ & SS & 1 & 17000 & 223.68 \\
\hline 12 & Membrane housing & $1 \mathrm{~m}$ long & Nil & 4 & 8800 & 115.79 \\
\hline 13 & Membrane module & $\begin{array}{l}4 " \text { dia × 40" } \\
\text { long }\end{array}$ & UF & 4 & 46000 & 605.26 \\
\hline 14 & Control panel & Nil & SS & 1 & 5800 & 76.32 \\
\hline 15 & Flow meter & Nil & Nil & 2 & 1300 & 17.11 \\
\hline 16 & Pressure gauge & Nil & Nil & 1 & 725 & 9.54 \\
\hline 17 & TDS meter & Nil & Nil & 1 & 1200 & 15.79 \\
\hline 18 & Permeate tank & 1000 & Plastic & 1 & 7000 & 92.11 \\
\hline 19 & Dosing pump & $0.025 \mathrm{HP}$ & Nil & 1 & 4500 & 59.21 \\
\hline \multirow[t]{2}{*}{20} & Piping (lot) & Nil & CPVC & 1 & 5500 & 72.37 \\
\hline & & & & Total & 420175 & 5528.62 \\
\hline
\end{tabular}


Table 4

Operation and maintenance cost of UF system

\begin{tabular}{|ll|}
\hline Cost component & MBR \\
\hline Feed capacity (Iph) & 1000 \\
\hline Permeate capacity (Iph) & 550 \\
\hline \% Recovery & 0.55 \\
\hline Operating cost & \\
\hline Membrane module replacement cost & \\
\hline No. of membrane modules (4" x 40" long) & 4 \\
\hline Price per membrane module (USD) & 151.32 \\
\hline Total membrane module replacement cost (USD) & 605.28 \\
\hline Duration of replacement (years) & 3 \\
\hline No. of working hours per day & 15 \\
\hline Cost/h (USD) & 0.037 \\
\hline Cartridge replacement cost & \\
\hline No. of cartridges & 2 \\
\hline Price per cartridge (USD) & 3.95 \\
\hline Total cartridge replacement (USD) & 7.9 \\
\hline Duration of replacement (days) & 301 \\
\hline No. of working hours per day & 15 \\
\hline Cost/h (USD) & 0.018 \\
\hline Power cost & 0.145 \\
\hline Feed pump (kW) & \\
\hline High-pressure pump (kW) & \\
\hline Dosing system (kW) & \\
\hline Total power consumption (kW) & \\
\hline Total power cost (USD) (@Rs 6 unit) & \\
\hline Chemical consumption & \\
\hline Antiscalant dosing (ppm) & \\
\hline Dosage (L/h) & \\
\hline
\end{tabular}




\begin{tabular}{|ll|}
\hline Cost component & MBR \\
\hline Cost/L (USD) & 2.105 \\
\hline Cost/h (USD) & 0.021 \\
\hline CIP chemicals (Citric acid, EDTA, NaOH) & \\
\hline Frequency (days) & 7 \\
\hline Hourly cost of cleaning chemicals (USD) & 0.028 \\
\hline Total cost of CIP per hour (USD) & 0.049 \\
\hline Labor cost per hour (USD) & 0.29 \\
\hline Total operating cost per hour (USD) & 0.542 \\
\hline Total operating cost per year (USD) & 3957.84 \\
\hline Depreciation cost (assuming 10\% of capital cost) (USD) & 772 \\
\hline Interest (10\% of capital cost) (USD) & 772 \\
\hline Total cost per year (USD) & 5501.84 \\
\hline Permeate & \\
\hline Quantity (LPH) & 550 \\
\hline Operation time (h) & 15 \\
\hline Quantity of permeate generated in 1 year (L/year) & $3,011,250$ \\
\hline Cost of permeate per liter (USD) & 0.00183 \\
\hline Cost of permeate per liter (Paisa) & 12.42 \\
\hline If sold at 2.5 $\times 10$ - 3 USD per liter, then & 7528.125 \\
\hline Annual profit (USD) & 2026.29 \\
\hline Payback period (years) & 2.72 \\
\hline
\end{tabular}

\section{Conclusions}

In the present study reveals, the feasibility of methanol coagulant for pretreatment followed by sidestream AMBR to effectively remove the turbidity, conductivity, TDS, moderate level COD present in RGW for water recovery and its reuse. Synthesis of HF - UF membrane was used in AMBR. The membranes were indigenous synthesised and characterization to illustrates the structural, nature and surface and cross-sectional morphologies of the membrane. Before subjecting to AMBR the RGW effluent was pretreated with $\mathrm{HCl}$. Methanol and ethanol coagulant and integrated laboratory HF - UF module to know the coagulant and membrane performance. The methanol coagulation process integrated with HF - UF 
achieved $78.6 \%$ COD. Therefore, the process was successfully integrated with AMBR. The methanol and pre-treatment followed by AMBR was remove $96 \%$ turbidity and $91 \%$ conductivity, $96.4 \%$ COD. Further, the effluent $\mathrm{pH}$ was increased from acidic medium to neutral (7.04) for membrane longevity and safety. Finally, the cost estimation of the pilot scale process was calculated and for $15 \mathrm{~h}$ operating time of the bioreactor.

\section{Declarations}

\section{Acknowledgements}

The First author Shaik Nazia thankful to the Council of Scientific and Industrial Research (CSIR) and Indian Institute of Chemical Technology (IICT) - Royal Melbourne Institute of Technology (RMIT) under the collaboration program providing an opportunity and funding as a research fellow.

\section{Authors' contributions}

All authors contributed in experimental work and in paper drafting, corrections to the final structure.

\section{Funding}

The author is grateful to the IICT - RMIT program for supporting throughout the research work.

\section{Availability of data and materials}

No other source of data and materials were used in these studies.

\section{Competing interests}

There are no competing interests

\section{Author details}

${ }^{1}$ Membrane Separations Laboratory, Process Engineering \&Technology Transfer Division, CSIR - Indian Institute of Chemical Technology, Hyderabad, India-500007.

${ }^{2}$ School of Engineering, RMIT University, Melbourne, VIC 3000, Australia

${ }^{3}$ School of Science centre f Advanced Materials and Industrial Chemistry at RMIT University, Melbourne, VIC 3000, Australia

\section{References}

1. Nguyen ST. Mitigation of membrane fouling in microfiltration and ultrafiltration of activated sludge effluent for water reuse, 2012; Ph.D. Thesis, RMIT University, Melbourne, Australia, December 2012. 
2. Jin Z, Gong H, Temmink H, Nie H, Wu J, Zuo J, wang K. Efficient sewage pre - concentration with combined coagulation microfiltration for organic matter recovery. Chem Eng J. 2016; 292:130 - 138.

3. Koning JD, Bixio D, Karabelas A, Salgot M, Schafer A. Characterisation and assessment of water treatment technologies for reuse. Desalination,2018; 218: 92-104.

4. Wakte K, Zanan R, HingeV, Khandagale K, Nadaf A, Henry R. Thirty-three years of 2-acetyl-1-pyrroline, a principal basmati aroma compound in scented rice (Oryza sativa L.): A status review. J Sci Food Agric. 2017; 97:2: 384-395.

5. Mingyai S, Kettawan A, Srikaeo K,Singanusong R. Physicochemical and antioxidant properties of rice bran oils produced from coloured rice using different extraction methods. J Oleo Sci.2017; 66:6:565572 .

6. Nierle W, Baya AWE, Wolf J. Loss of substances accompanying rice cooking in excess water. Chemie, Mikrobiologie, Technologie der Lebensmittel.1981;7: 9-12.

7. Lens P, Hulshoff PL, Wilderer P, Asano T. Water recycling and resource recovery in industry: Analysis, technologies, and implementation. IWA Publishing.2002,

8. Zeng Z, Liu J, Savenije HHG. A simple approach to assess water scarcity integrating water quantity and quality. Ecol Indic. 2013; 34: 441- 449.

9. Rathoure AK, Dhatwalia VK. Toxicity and waste management using bioremediation. IGI Global, Hershey.2016.

10. Morin-Crini N, Crini G. Eaux industrielles contaminées. PUFC, Besançon.2017.

11. Brunetti A, Macedonio F, Barbieri G, Drioli E. Membrane engineering for environmental protection and sustainable industrial growth: Options for water and gas treatment. Environ Eng. 2015; 20:4: 307 -

12. Krzeminski P,Tomei MC, Karaolia P, Langehoff A, Almeida CMR, Felis E, Gritten F, Andersen HR, Fernandes T, Manaia CM, RizzoL, Fatta-Kassinos D. Performance of secondary wastewater treatment methods for the removal of contaminants of emerging concern implicated in crop uptake and antibiotic resistance spread: A review. J Sci Total Environ. 2019,15: 1052- 1081.

13. Flaherty KA,Smick K.Thermophilic anaerobic treatment of a wheat starch processing wastewater: $A$ full-scale case history. Dairy Food Envi Sanitation. 1989;9: 629 -

14. Turk SS, Petrinic I, Simonic M. Laundry wastewater treatment using coagulation and membrane filtration. Resour Conserv Recy. 2005; 44 :2: 185 - 196.

15. Praneeth K, Suresh KB, Tardio J, Sridhar S. Water recovery from domestic kitchen effluent through membrane separation processes Chemeca 2014: Processing excellence; Powering our future.

16. Hey T, Bajraktari N, Davidsson A, Vogel, J, Madsen HT, Helix-Nielsen, C, Jansen, JC, Jonsson K. Evaluation of direct membrane filtration and direct forward osmosis as concepts for compact and energy-positive municipal wastewater treatment. Environ Technol.2018; 39: 3: 264-276

17. Zavala MAL, Perez LBS, Reynoso-Cuevas L, Funamizu, N.Pre-filtration for enhancing direct membrane filtration of greywater from washing machine discharges. Ecol Eng.2014; 64: 116-119. 
18. Boykin JC, Soerens, TS, Siebenmorgen TJ. Treatment of rice cooker wastewater and recovery of byProducts by membrane microfiltration. Am Soc of Agric Eng.2005; ISSN 0883-8542,21;4: 689 - 694 .

19. Sayanthan S, Thusyanthy Y. Rice Parboiling and Effluent Treatment Models; a Review. Int J Res Stud Agric Sci. ISSN No. 2454-6224; 4; 5: 17-23.

20. Bovas J, James P. Development of a hybrid anaerobic bioreactor for treatment and energy conversion of rice mill effluent. Proceedings of 22nd Kerala Science Congress. 2010;28-31: 516 -

21. Mahanta CL, Bhattacharya KR. Thermal degradation of starch in parboiled rice. Starch Stärke.1989; 41: 91-94.

22. Choudhary M, Majumder S, Neogi S. Studies on the treatment of rice mill effluent by electrocoagulation. Separa Sci Tech.2015; 50: 505-511.

23. Bharathiraja Yogendran D, RanjithKumarR, Chakravarthy M, Palani S. Biofuels from sewage sludge A review. Int J Chem Tech Res. 2014; 6: 4417-4427.

24. Judd S. Fouling control in submerged membrane bioreactor. Water Sci Technol. 2005;51:27-34.

25. Kawasaki K, Matsuda A, Tanabe S, Katagiri N, Irtiani E. Effect of suction pressure and aeration pressure on the hollow fibre microfiltration of excess activated sludge. Process Saf Environ.2007;85: 176-180.

26. Chang IS, Le - Clech P, Jefferson B, Judd S. Membrane fouling in membrane bioreactor for wastewater treatment. J Environ Eng.2002;12811:1018-1029.

27. Gkotsis PK, Banti DC, Peleka EN, Zouboulis Al, Samara PE. Fouling issue in membrane bioreactor (MBRs) for wastewater treatment: major mechanisms, prevention and control strategies, processes. $2014 ; 2: 795-866$.

28. Ashish T, Omprakash S. Study of characteristics and treatment of dairy industry wastewater. J Appl Environ Microb. 2014;2:1: 16-22.

29. Sioutopoulos DC, Yiantsios SG, Karabelas AJ. Relation between fouling characteristics of ro and uf membranes in experiments with colloidal organic and inorganic species. J Membr Sci. 2010; 350: 62-82.

30. Shi TF, Wei J, An LJ, Li BY. Molecular dynamics simulation of sub-transition for polyethersulfone, Macromol Theor Simul. 2001;10 :232-236.

31. Ellis B, Polymers: A Property Database, Chapman \& Hall/CRC Press, Boca Raton, FL, 2000, continually updated.

32. Venkata Swamy B, Madhumala M, Prakasham RS, Sridhar S. Processing of biscuit industrial effluent using thin film composite nanofiltration membrane. Des Monomer Polym.2016; 19:1:47 - 55.

\section{Figures}




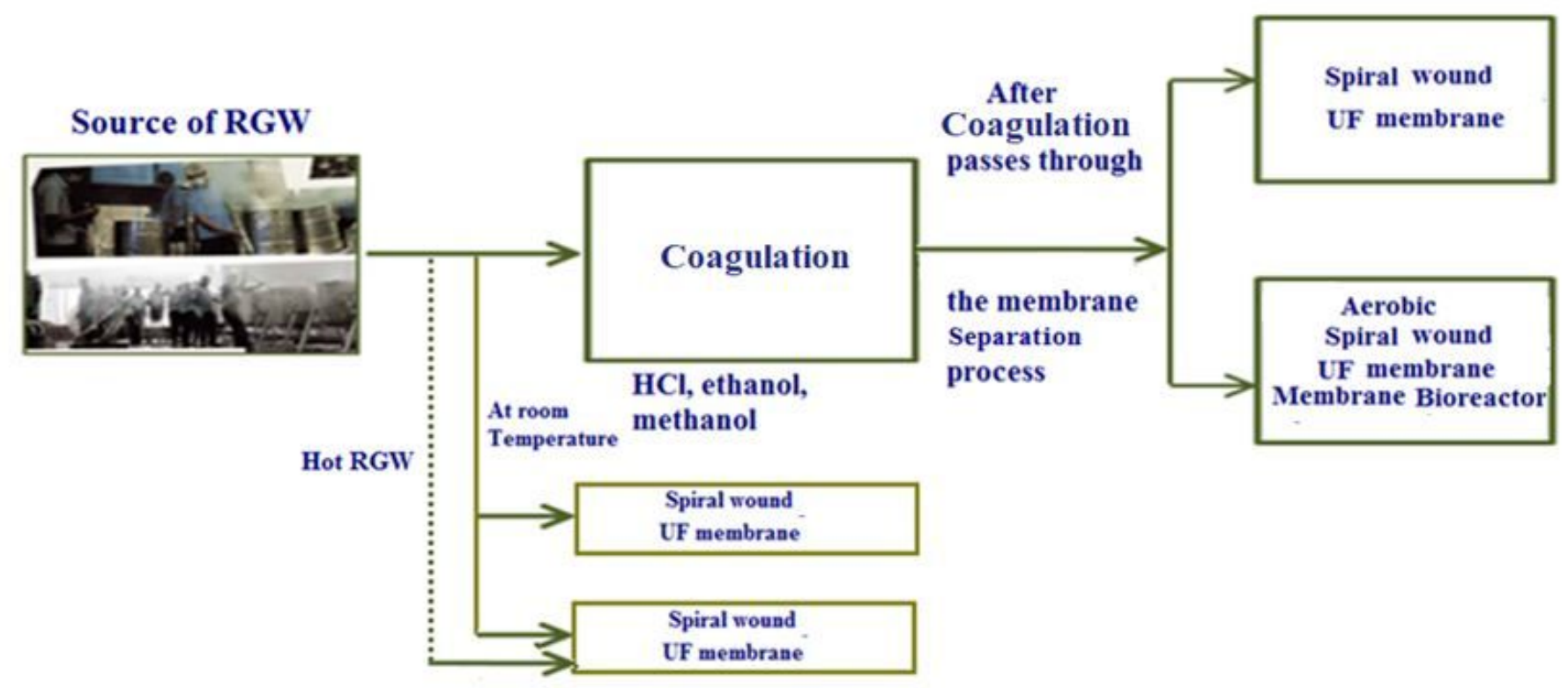

(a)
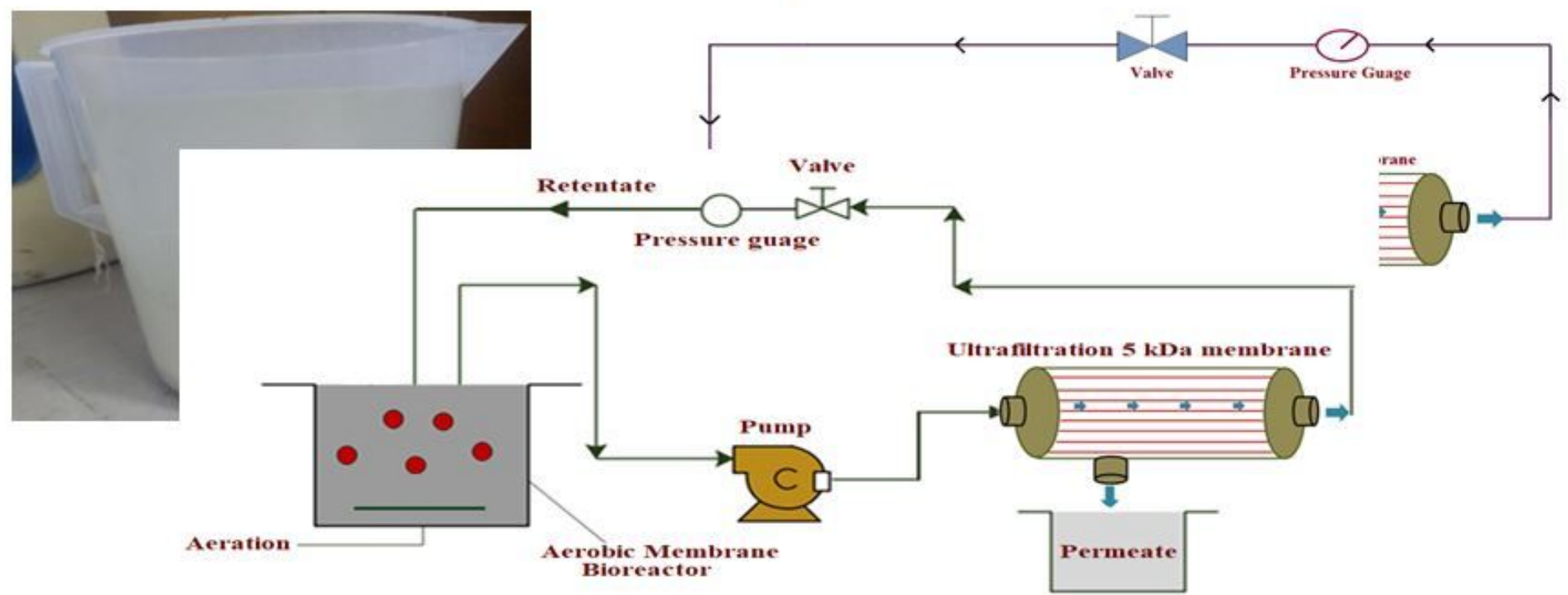

(b)

(c)

(d)

\section{Figure 1}

(a) Overall process flow diagram for the treatment of Rice Gruel Wastewater (RGW), (b) RGW after pretreatment with methanol, Process flow diagram of (c) spiral wound UF system and (d) AMBR (aerobic membrane bioreactor) system. 


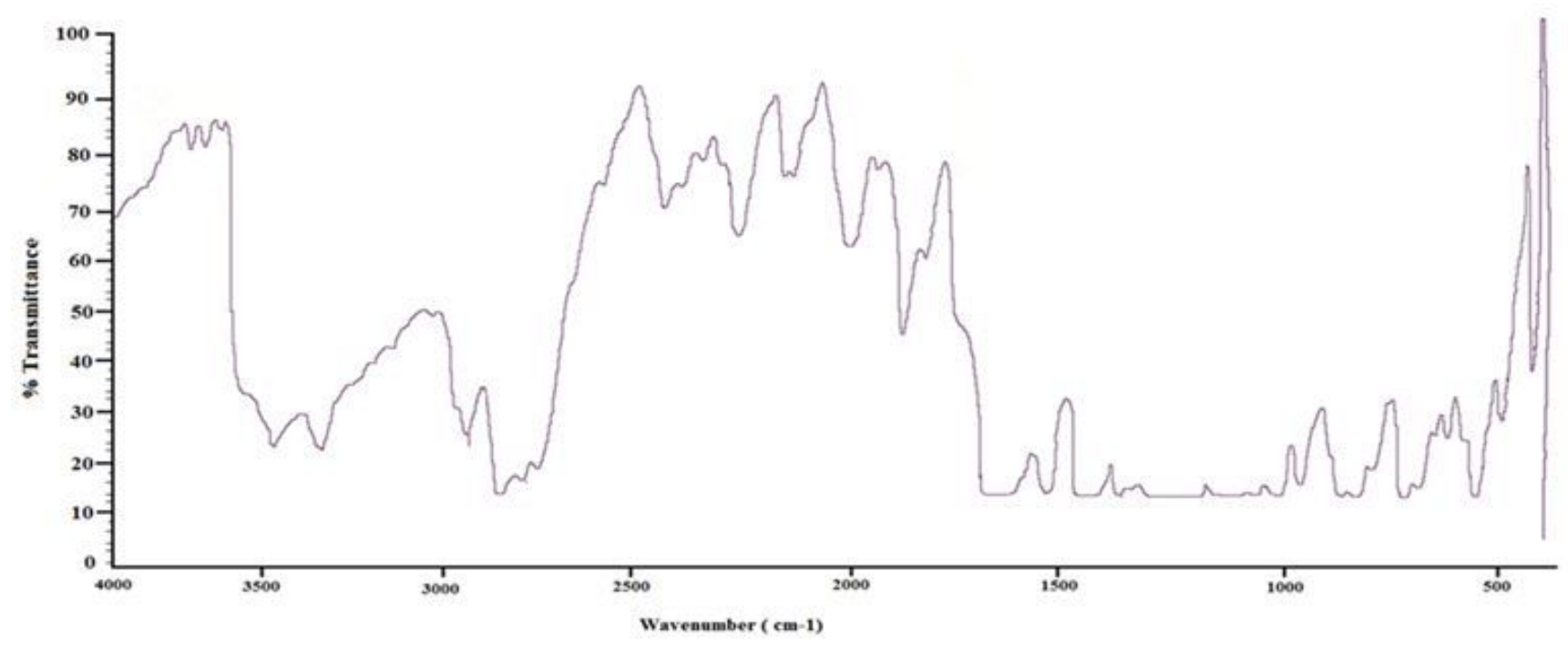

(a)

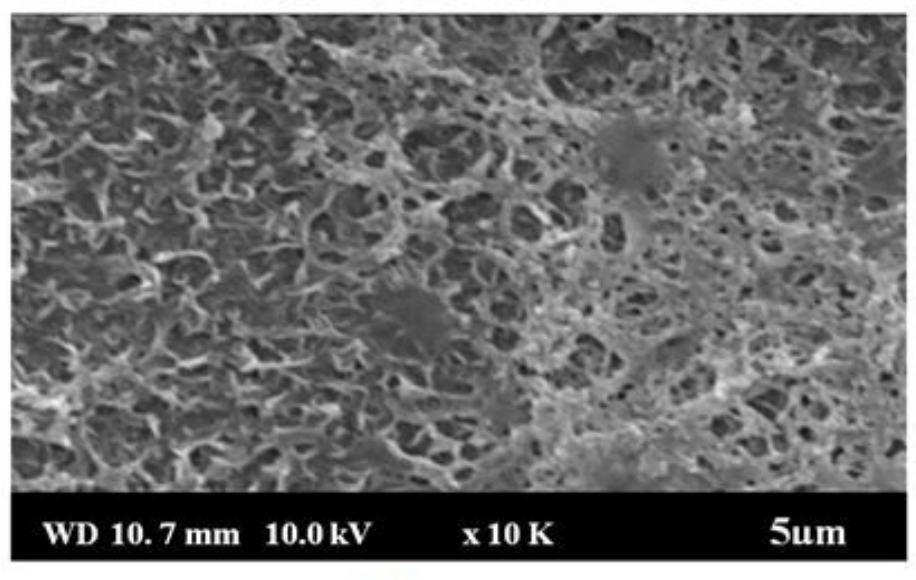

(b)

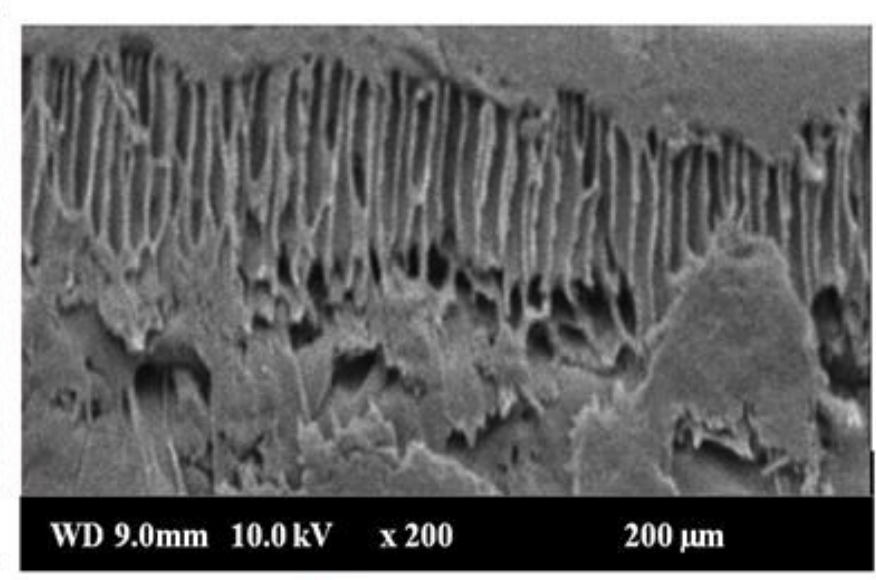

(c)

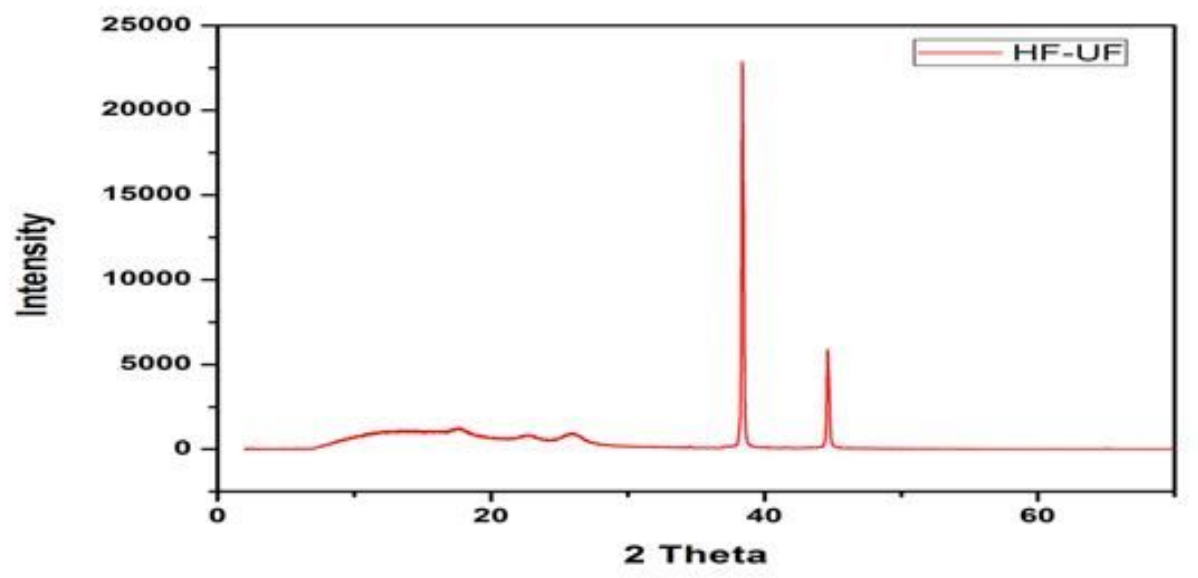

Figure 2

(a) FTIR, (b) SEM image of surface (c) cross-sectional of HF - UF membrane and (d) XRD pattern of HF UF membrane 


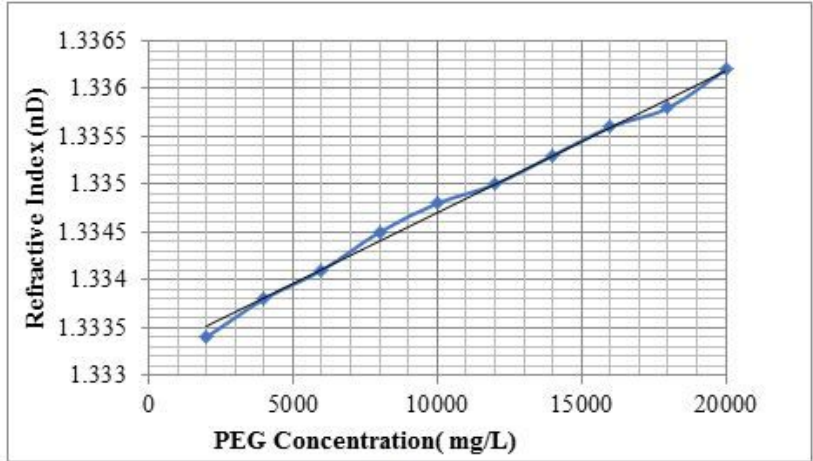

(a)

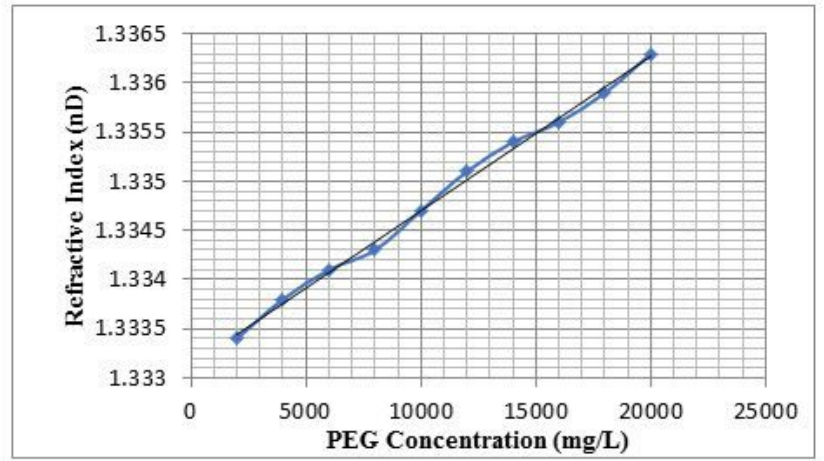

(b)

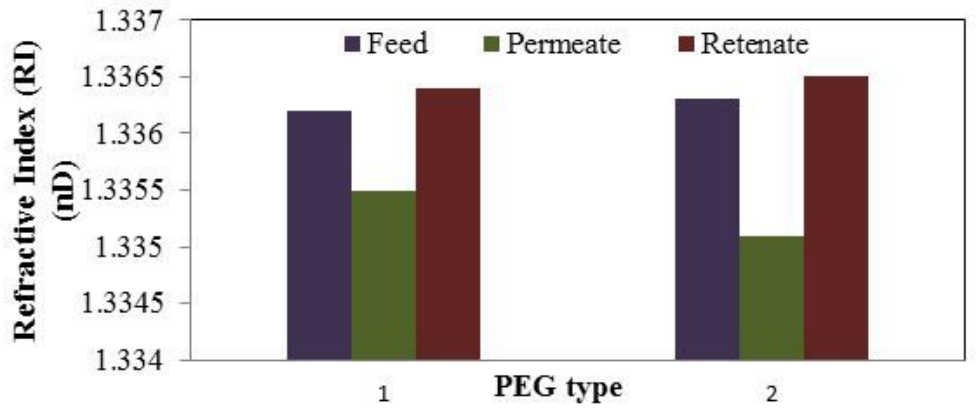

(c)

\section{Figure 3}

Effect of PEG concentration with Refractive Index (a) 6,000 (b) 4,000 and (c) Effect of Parameters with the Refractive Index ( 1 and 2 denote the PEG type 6,000 and 4,000 Da, respectively). 


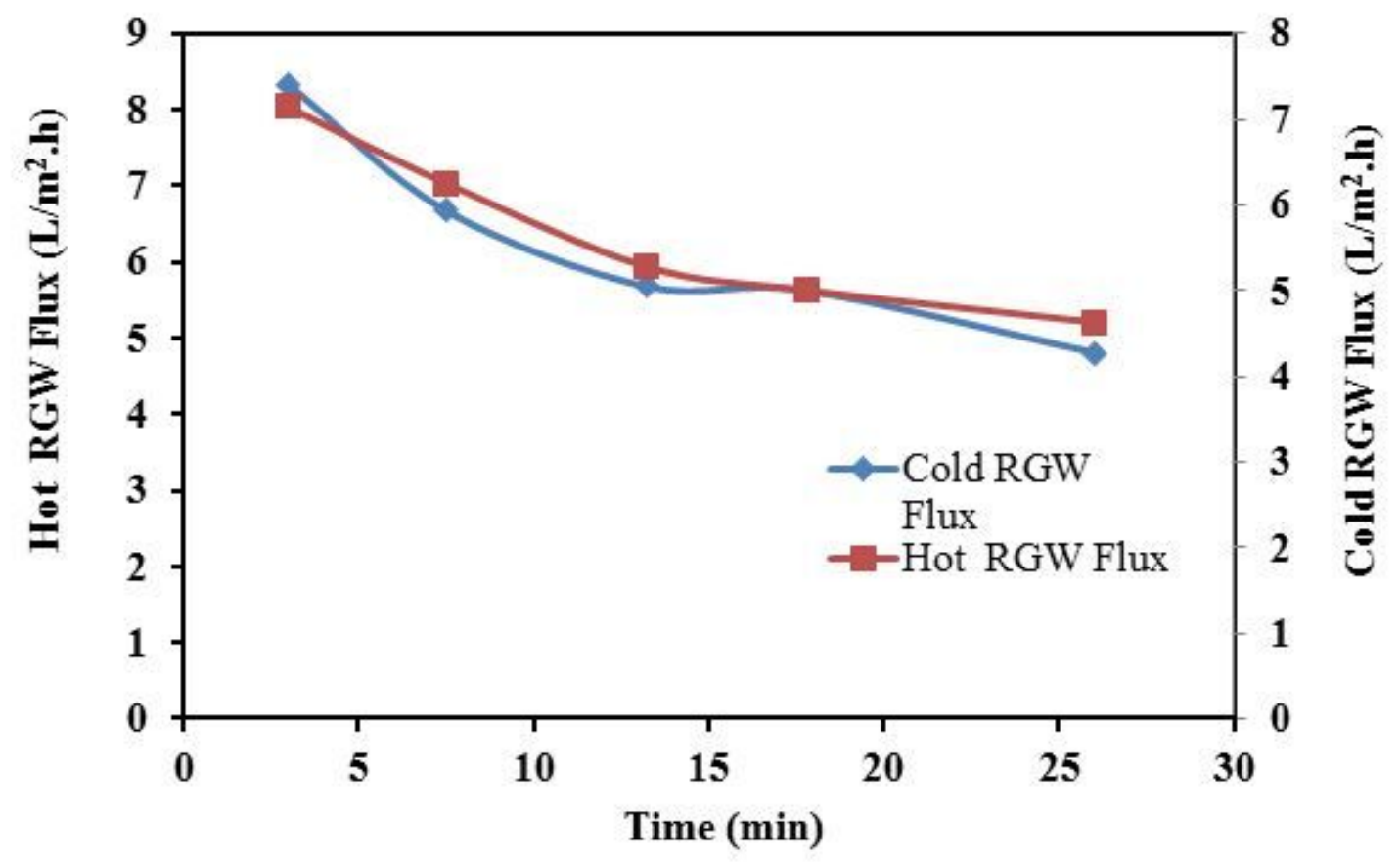

(a)

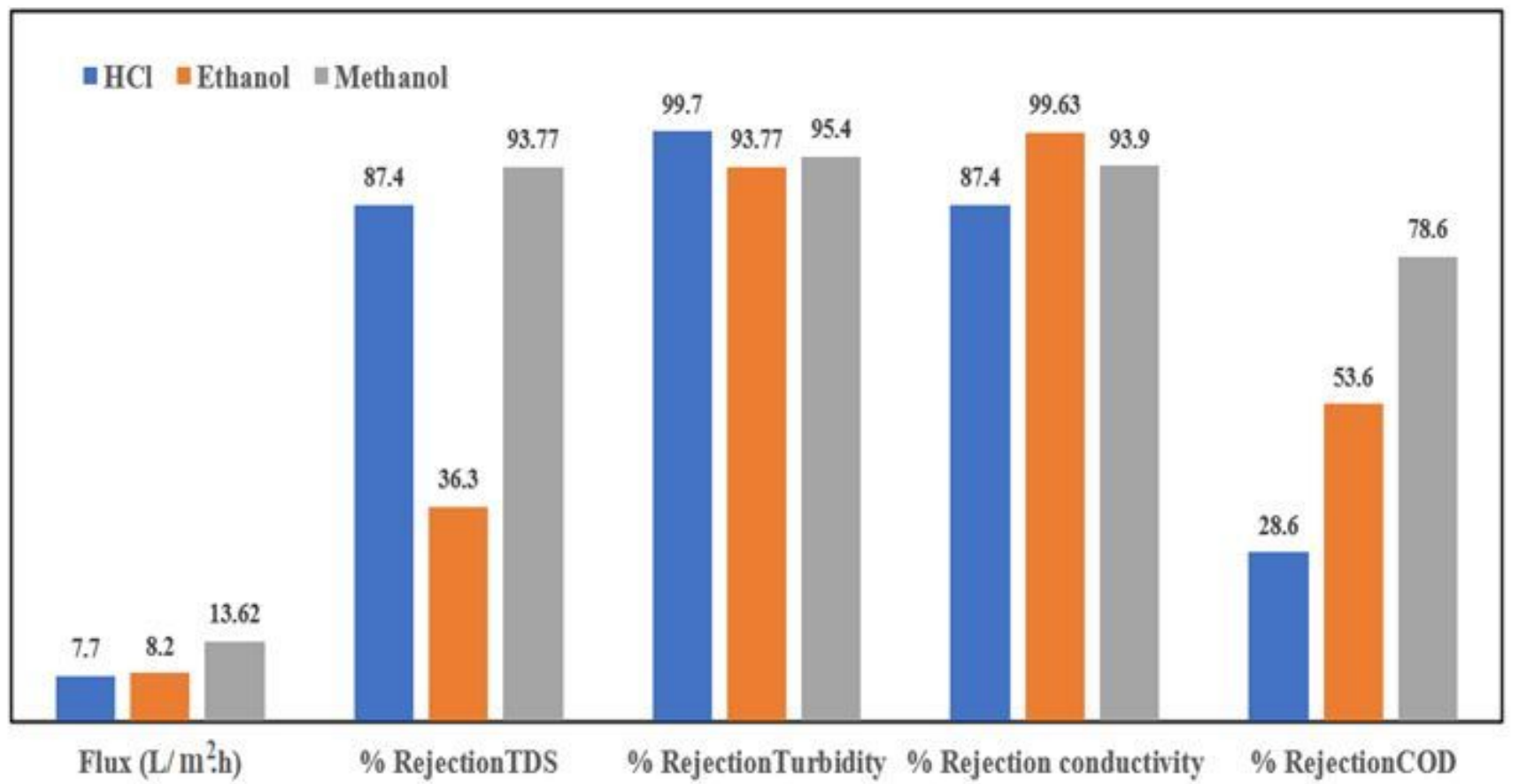

Figure 4

(a) Effect of operating time on permeate flux at room temperature and $80^{\circ} \mathrm{C}$, (b) Permeate flux and \% rejection parameters after coagulation integrated HF - UF membrane. 


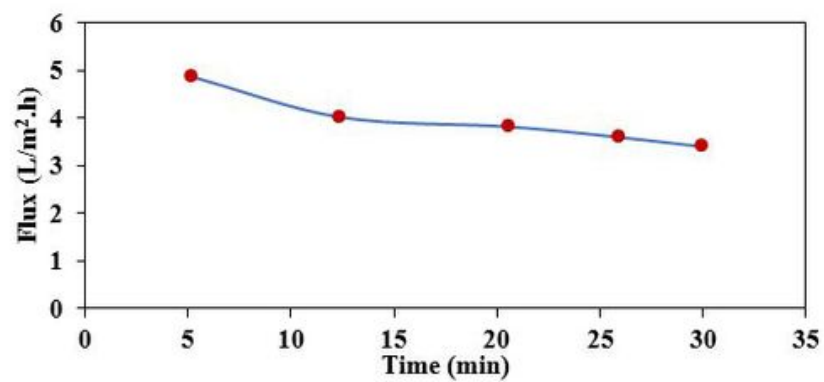

(a)

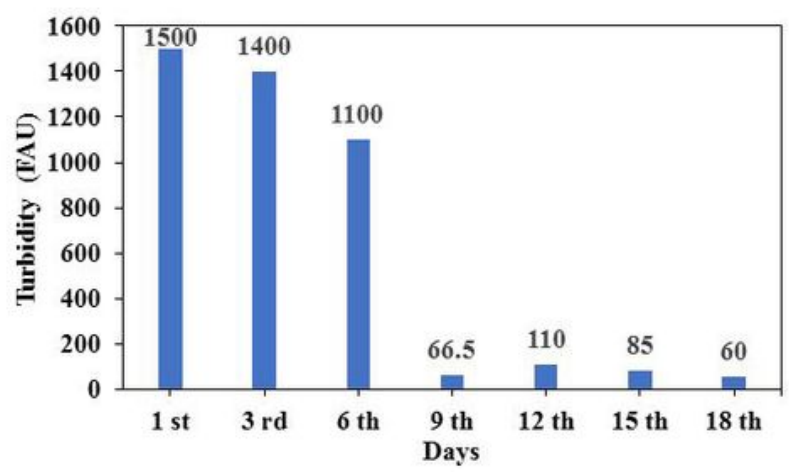

(b)

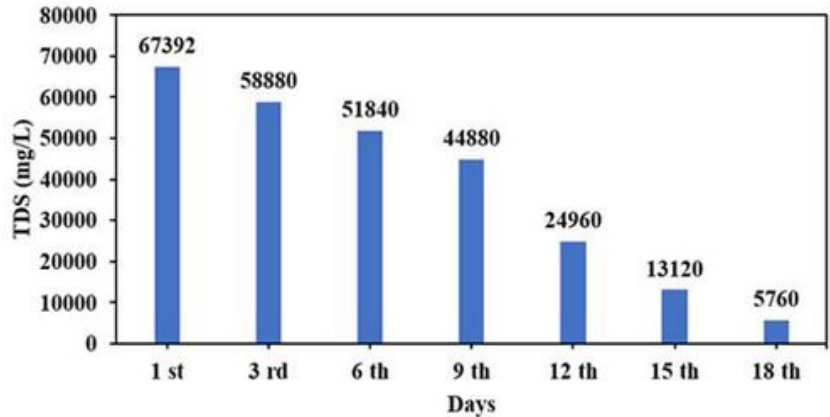

(d)

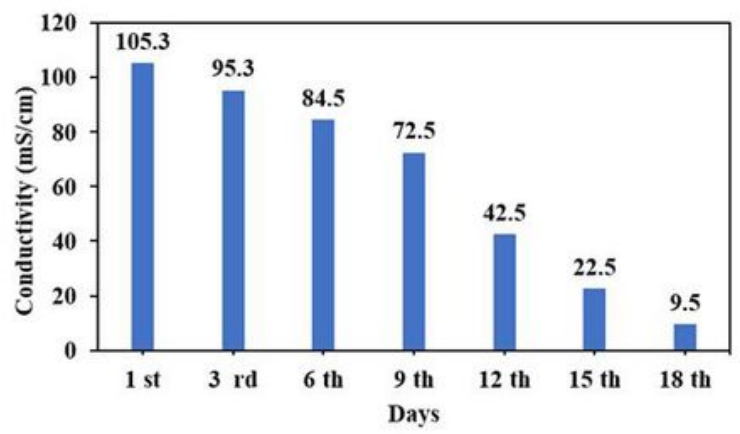

(c)

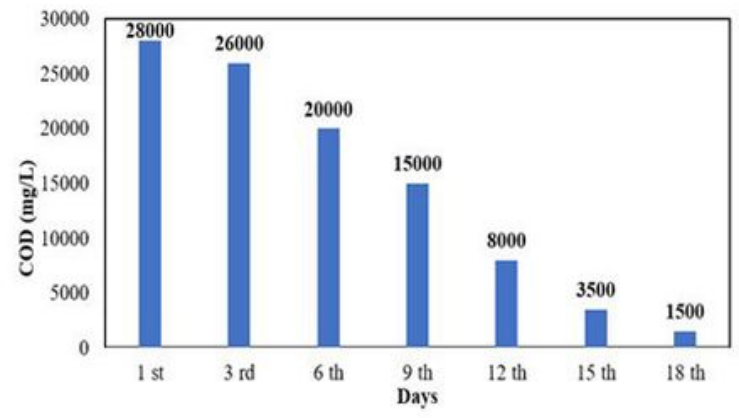

(e)

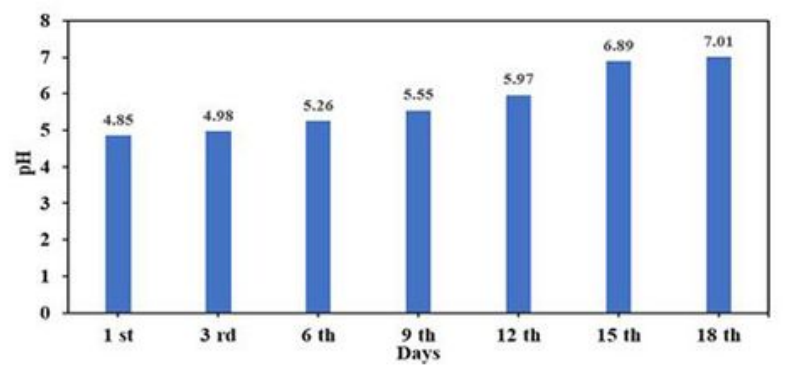

(f)

\section{Figure 5}

(a) Effect of operating time on permeate flux, effect of operating days on (b) Turbidity (c) conductivity (d) TDS (e) COD and (f) $\mathrm{pH}$ in permeate by AMBR process. 


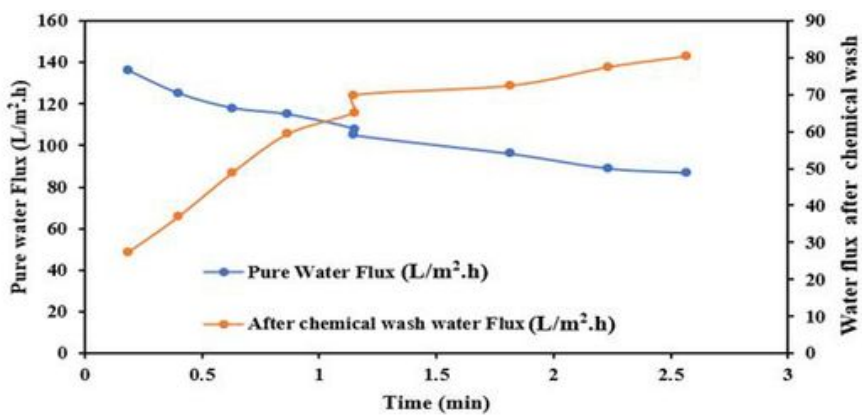

(a)

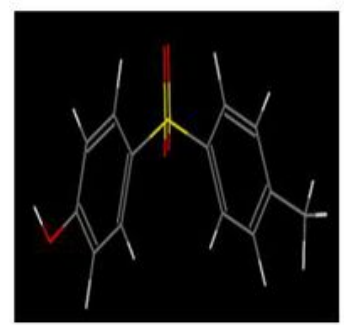

(b)

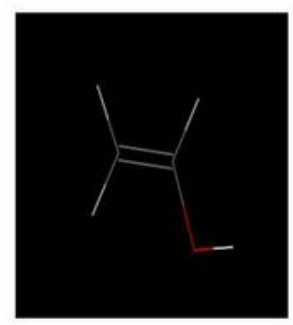

(c)

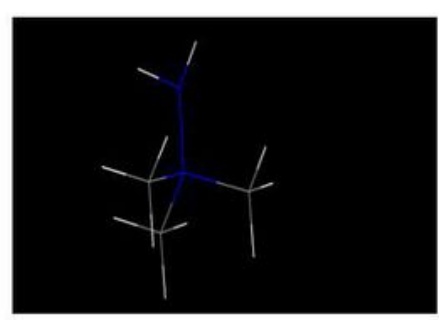

(d)

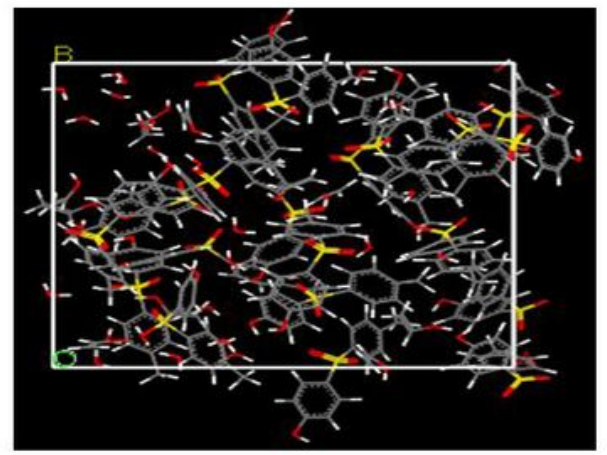

(e)

Enegris. Snudaton Tine

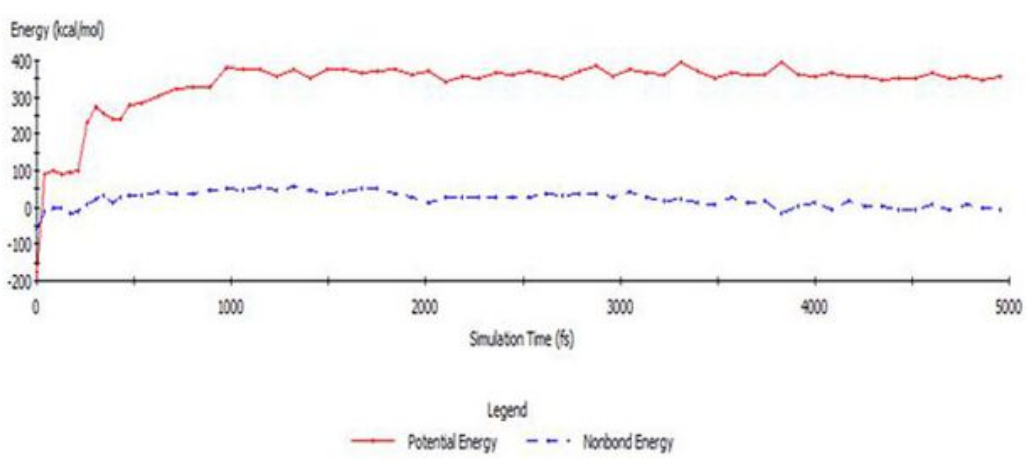

(f)

Figure 6

(a) Effect of operating time on pure water flux and water flux after chemical wash, 3 D structure of (b) PES, (c) PVA, (d) DMF, (e) A minimized structures of PES/PVA and (f) Minimization energy of PES/PVA structure 